\title{
DIÁLOGOS ENTRE O CONHECIMENTO POPULAR E CIENTÍFICO
}

\author{
Andressa de Jesus Araújo Ramos ${ }^{1}$ \\ João Batista Santiago Ramos ${ }^{2}$
}

\begin{abstract}
RESUMO. A ciência moderna nos formou de maneira insuficiente em relação a nossa existência no mundo, visto que, tradicionalmente, se limitava, apenas, em classificar o conhecimento em "científico" e "não científico". Porém com o surgimento da ciência pós-moderna as inquietações dos pesquisadores contemporâneos não se restringem à mera classificação de conhecimentos, mas sim em incluir e valorizar essa multiplicidade de saberes. Dessa forma, este trabalho, vinculado ao Programa de Pós-graduação em Estudos Antrópicos na Amazônia (PPGEAA), reflete sobre os diálogos entre o conhecimento popular e científico na esfera acadêmica. O referencial teórico desta pesquisa ampara-se em: Santos (2008), Santos e Filho (2008). Sendo assim, acredita-se que este estudo trará discussões relevantes no que tange a interação entre o conhecimento popular e científico na academia, uma vez que, a inclusão e a valorização do conhecimento popular na esfera acadêmica a partir da ecologia de saberes - que se trata da intensificação da pesquisa-ação -, promove uma transformação epistemológica no interior da universidade.
\end{abstract}

Palavras chave: Diálogos; Conhecimento Popular; Conhecimento Científico.

\section{DIALOGUES BETWEEN POPULAR AND SCIENTIFIC KNOWLEDGE}

\begin{abstract}
Modern science formed us insufficiently in relation to our existence in the world, since traditionally it was limited only to classifying knowledge as "scientific" and "unscientific." But with the rise of postmodern science the concerns of contemporary researchers are not limited to the mere classification of knowledge, but rather to include and value this multiplicity of knowledge. Thus, this work, linked to the Postgraduate Program in Anthropic Studies in the Amazon (PPGEAA), reflects on the dialogues between popular and scientific knowledge in the academic sphere. The

\footnotetext{
1 Mestranda do Programa de Pós-Graduação em Estudos Antrópicos da Amazônia (PPGEAA/UFPA) Campus de Castanhal. Bolsista da Coordenação de Aperfeiçoamento de Pessoal de Nível Superior (CAPES).adjaramos@gmai.com

${ }^{2}$ Orientador do artigo. Docente do Programa de Pós-Graduação em Estudos Antrópicos da Amazônia (PPGEAA/ UFPA) - Campus de Castanhal. Professor de Filosofia da Faculdade de Pedagogia na UFPACampus de Castanhal. Coordenador Geral da UFPA-Campus de Castanhal. Doutor em filosofia pela Universidade do Porto-Portugal.
} 
theoretical reference of this research is based on: Santos (2008), Santos e Filho (2008). Thus, it is believed that this study will bring about relevant discussions regarding the interaction between popular and scientific knowledge in the academy, since, the inclusion and appreciation of popular knowledge in the academic sphere from the ecology of knowledge - that is deals with the intensification of action research -, promotes an epistemological transformation within the university.

Keywords: Dialogues; Knowledge Popular; Scientific knowledge.

\section{DIÁLOGOS ENTRE EL CONOCIMIENTO POPULAR Y CIENTÍFICO}

Resumen. La ciencia moderna nos formó de manera insuficiente en relación a nuestra existencia en el mundo, ya que tradicionalmente sólo se limitaba a clasificar el conocimiento en "científico" y "no científico". Pero con el surgimiento de la ciencia post-moderna las inquietudes de los investigadores contemporáneos no se restringen a la mera clasificación de conocimientos, sino en incluir y valorar esa multiplicidad de saberes. De esta forma, este trabajo, vinculado al Programa de Postgrado en Estudios Antrópicos en la Amazonía (PPGEAA), refleja sobre los diálogos entre el conocimiento popular y científico en la esfera académica. El referencial teórico de esta investigación se ampara en: Santos (2008), Santos e Hijo (2008). Siendo así, se cree que este estudio traerá discusiones relevantes en lo que se refiere a la interacción entre el conocimiento popular y científico en la academia, una vez que, la inclusión y la valorización del conocimiento popular en la esfera académica a partir de la ecología de saberes - que si se trata de la intensificación de la investigación-acción-, promueve una transformación epistemológica en el interior de la universidad.

Palabras clave: Diálogos; Conocimiento popular; Conocimiento; Científico.

\section{Introdução}

"O conhecimento universitário, científico, é importante, mas não basta".

(Boaventura de Souza Santos)

A ciência moderna ${ }^{3}$, de acordo com Santos (2008, p.88), nos instruiu de forma insuficiente no que se refere a nossa existência no planeta e que esse pouco “(...) por

\footnotetext{
${ }^{3}$ De acordo com Santos (2008), a ciência moderna se estabeleceu a partir da revolução científica do século XVI e foi ampliada nos séculos subsequentes principalmente no domínio das ciências naturais. $\mathrm{O}$ modelo de racionalidade científica está consolidado na teoria heliocêntrica da movimentação dos planetas de Copérnico, bem como, nas leis de Kepler em relação as órbitas dos planetas, nas leis de Galileu acerca
} 
mais que se amplie, será sempre exíguo porque a exiguidade está inscrita na forma de conhecimento que ele constitui".

$\mathrm{Na}$ verdade, a ciência moderna determina “(...)conhecimentos e desconhecimentos. Se faz do cientista um ignorante especializado faz do cidadão comum um ignorante generalizado" (SANTOS, 2008, p.88, grifo nosso).

Por outro lado, a ciência pós-moderna ${ }^{4}$, segundo Santos (2008, p. 88), compreende que “(...) nenhuma forma de conhecimento é, em si mesma, racional; só a configuração de todas elasé racional". A ciência pós-moderna se arrisca a "dialogar com outras formas de conhecimento deixando-se penetrar por elas" (SANTOS, 2008, p.88).

Dessa forma, este trabalho, tendo em foco o pensamento do sociólogo Boaventura Santos, refletir sobre os diálogos entre o conhecimento popular e científico.

Boaventura de Sousa Santos é doutor em Sociologia do Direito pela Universidade de Yale (1973) e, atualmente, é diretor do Centro de Estudos Sociais da Universidade de Coimbra e coordenador científico do Observatório Permanente da Justiça Portuguesa.

Além disso, o pesquisador conduz o projeto de investigação ALICE - Espelhos estranhos, lições imprevistas, definindo para a Europa um novo modo de partilhar as experiências o mundo. Esse projeto é subsidiado pelo Conselho Europeu de Investigação (ERC), que é considerado como um dos mais conceituados e disputados financiamentos internacionais no que se refere a investigação científica de excelência no continente europeu.

Boa ventura Santos se interessa e pesquisa sobre a Epistemologia, sociologia do direito, teoria pós-colonial, democracia, interculturalidade, globalização, movimentos sociais, direitos humanos. Seus inúmeros trabalhos foram publicados em diversas línguas, tais como: em português, inglês, italiano, espanhol, alemão, francês, chinês e romeno.

da queda dos corpos, na ampla sinopse da ordem cósmica de Newton e por fim na consciência filosófica que lhe atribuem Bacon e especialmente Descartes.

${ }^{4}$ Segundo Santos (2008), a ciência pós-moderna não obedece uma forma unidimensional, de fácil identificação, pois o seu estilo é uma composição de estilos fundada mediante ao critério e a imaginação própria do cientista. Na verdade, a ciência pós-moderna, tenta dialogar com outras representações de conhecimento deixando-se penetrar por elas. 


\section{A (re)significação do conhecimento popular ${ }^{5}$}

Conforme Santos (2008), enquanto a ciência moderna apresentou uma aversão ao senso comum, uma vez que, o considerou como algo superficial, imaginário e infiel. A ciência pós-moderna, por sua vez, objetiva o recuperar, pois “(...)reconhece nesta forma de conhecimento algumas virtualidades para enriquecer a nossa relação com o mundo" (SANTOS, 2008, p.89).

Na ciência pós-moderna, conforme Santos (2008), o conhecimento proveniente do senso comum ${ }^{6}$, isto é, o conhecimento vulgar e prático, é o que diariamente dirige nossos atos e dar sentido à nossa história.

Santos (2008, p.89) elucida que o conhecimento do senso comum tem uma tendência em ser mistificado e mistificador, pois tem “(...) uma dimensão utópica e libertadora que pode ser ampliada através do diálogo com o conhecimento científico". Dessa forma, o senso comum é:

(...) transparente e evidente; desconfia da opacidade dos objectivos tecnológicos e do esoterismo do conhecimento em nome do princípio da igualdade do acesso ao discurso, à competência cognitiva e à competência linguística. $\mathrm{O}$ senso comum é superficial porque desdenha das estruturas que estão para além da consciência, mas, por isso mesmo, é exímio em captar a profundidade horizontal das relações conscientes entre pessoas e entre pessoas e coisas. O senso comum é indisciplinar e imetódico; não resulta de uma prática especificamente orientada para o produzir; reproduz-se espontaneamente no suceder quotidiano da vida. $O$ senso comum aceita o que existe tal como existe; privilegia a acção que não produza rupturas significativas no real. Por último, o senso comum é retórico e metafórico; não ensina, persuade. (SANTOS, 2008, p. 89-90)

De acordo com Santos (2008, p.90), na ciência moderna “(...) a ruptura epistemológica simboliza o salto qualitativo do conhecimento do senso comum para o conhecimento científico". Em contrapartida, na ciência pós-moderna é o reverso, pois o “(...) conhecimento científico pós-moderno só se realiza enquanto tal na medida em que se converte em senso comum". (SANTOS, 2008, p. 90-91).

\footnotetext{
${ }^{5}$ Neste artigo encontra-se terminologias, tais como "Conhecimento do senso comum", de Santos (2008) e "Saber popular", de Silva e Neto (2015), porém adotamos a nomenclatura "Conhecimento popular", pois traduz de forma mais significativas o sentido real de nosso trabalho, que é da valorização de tal conhecimento.
} 
Sendo assim, vale esclarecer que o senso comum, de acordo com Santos (2008, p. 91), não desfavorece o conhecimento que fornece tecnologia, porém compreender que assim como “(...) o conhecimento se deve traduzir em autoconhecimento, o desenvolvimento tecnológico deve traduzir-se em sabedoria de vida".

\section{Por uma ecologia dos saberes nas universidades}

A ecologia de saberes, de acordo com Santos e Filho (2008), é uma intensificação da pesquisa-ação ${ }^{6}$, isto é, algo que provoca uma transformação epistemológica no interior da universidade e, que não pode ser estabelecida por lei. Ainda conforme os autores, tal transformação precisa gerar ambientes institucionais que promovam a facilidade e o incentivo a sua ocorrência. $\mathrm{Na}$ verdade, a ecologia de saberes é:

(...)uma forma de extensão ao contrário, de fora da universidade para dentro da universidade. Consiste na promoção de diálogos entre o saber científico ou humanístico, que a universidade produz, e saberes leigos, populares, tradicionais, urbanos, camponeses, provindos de culturas não ocidentais (indígenas, de origem africana, oriental, etc.) que circulam na sociedade. (SANTOS; FILHO, 2008 , p. 69, grifo nosso)

Santos e Filho (2008, p. 69, grifo nosso) ressaltam que a maioria das universidades, ao especializarem no conhecimento científico, que é o conhecimento "verdadeiro" colaboram para “(...)para a desqualificação e mesmo destruição de muito conhecimento não-científico e que, com isso, contribuiu para a marginalização dos grupos sociais que só tinham ao seu dispor essas formas de conhecimento".

Dessa forma, a pesquisa-ação e a ecologia de saberes “(...) são conjuntos de práticas que promovem uma nova convivência activa de saberes no pressuposto que todos eles, incluindo o saber científico, se podem enriquecer nesse diálogo" (SANTOS; FILHO, 2008, p. 70, grifo nosso). Sendo assim, implica:

(...) uma vasta gama de acções de valorização, tanto do conhecimento cientifico, como de outros conhecimentos práticos, considerados úteis, cuja partilha por pesquisadores, estudantes e grupos de cidadãos serve de base à criação de comunidades epistémicas mais amplas que

\footnotetext{
${ }^{6}$ A pesquisa-acção constitui “(...) na definição e execução participativa de projectos de pesquisa, envolvendo as comunidades e organizações sociais populares a braços com problemas cuja solução pode beneficiar dos resultados da pesquisa" (SANTOS, 2008, p. 68).
} 
convertem a universidade num espaço público de interconhecimento onde os cidadãos e os grupos sociais podem intervir sem ser exclusivamente na posição de aprendizes. (SANTOS; FILHO, 2008, p. 70)

\section{Diálogos entre o conhecimento popular e o científico}

O objetivo dessa seção é o de refletir sobre os diálogos entre o conhecimento popular e cientifico, considerando o pensamento do sociólogo Boaventura Santos, que propõe a ecologia dos saberes as universidades. O português, em um Ciclo de conferências que comemorava os 90 anos da UFMG, no dia 25 de abril de 2017, abordou inúmeros assuntos, tais como a interculturalidade, a democracia participativa, os movimentos sociais e os direitos humanos.

A conferência objetivava interrogar a hegemonia branca e ocidental em que o conhecimento científico está submerso, e chamou a atenção dos espectadores para a necessidade de entender os conflitos de poder no processo de produção científica.

Boaventura inconformado com a ciência moderna, defendeu que a universidade pública precisa ser o espaço-tempo de uma ecologia de saberes. A ecologia dos saberes, segundo ele é "como se fosse uma extensão ao contrário: não é levar o conhecimento da universidade para fora, mas identificar, valorizar e agregar conhecimentos que já circulam fora dos limites acadêmicos".

\section{Conhecimento popular sobre o parto}

Salve a parteira- Zé Vicente

Quando eu nasci, seu moço No sertão do Ceará Não tinha maternidade

E a cidade era longe demais Mãe Suzana me pariu Mãe Teresa me pegou Mãe das Dores me benzeu Mãe Laura me amamentou

Salve a parteira

Mãe caximbeira A mãe que me pegou

(Álbum: Zé Vicente- Nativo)

RPI Revista de Pesquisa Interdisciplinar, Cajazeiras, v. 3, n. 1, 15-27, jan/jul. de 2018. 
De acordo com Pereira (2011, p.03), antes do surgimento da medicina moderna, "as mulheres pariam seus filhos em casa". Ainda conforme a autora, os eventos que envolviam a gravidez, o parto e o cuidado com as crianças eram compreendidos por exercícios e gestos de uma cultura feminina, que permanecia distante da visão da Medicina.

No contexto tradicional, segundo Giddens (1995 apud Pereira, 2011, p.03), as parteiras atuavam "como guardiãs de alguns aspectos da memória coletiva", ou seja, a contínua reorganização do passado, possuindo como base o presente. A tradição então “(...) faz uso de rituais que a revitalizam no presente; essa reconstrução pode ser em parte individual, mas é essencialmente social e coletiva" (PEREIRA, 2011, P.03). Dessa maneira:

\begin{abstract}
Martins (2004) relata que, não obstante a carência de registros legados pelas parteiras, acredita-se, com base em informações provenientes de outras especialidades - como a Arte, a Antropologia, a Arqueologia, etc. - ser esta a profissão mais antiga do mundo. Circunscrito ao âmbito domiciliar e imerso culturalmente em tradições, rituais e crenças, todo o processo do parto e do nascimento era atendido pela parteira. Assim, a parteira pode ser considerada como a primeira pessoa a ter praticado a Medicina (DINIZ, 1997), administrando como parte de sua tarefa uma terapia ginecológica rudimentar. (PEREIRA, 2011, p.04, grifo nosso)
\end{abstract}

Os médicos, de acordo com Pereira (2011, p.04) passaram a demostrar “(...)um envolvimento maior com os procedimentos do parto e pós-parto", iniciando, assim, um período marcante na história do parto no Ocidente, que foi a incorporação das práticas das parteiras por médicos. Processo esse, que depois de um tempo “(...)passou a ser chamado nos estudos acadêmicos de 'medicalização do parto' , (PEREIRA, 2011, p.04).

\title{
Conhecimento popular sobre plantas que auxiliam no tratamento e/ou cura de doenças
}

“... E o seu fruto servirá de alimento e a sua folha de remédio”. (Velho Testamento - Ezequiel, 47:12)

Uma planta é considerada "medicinal", segundo Jorge (2009, p.16) quando tiver substâncias que possuem ação farmacológica, ou seja, "atuação dos componentes 
químicos das plantas no organismo". Conforme a pesquisadora, tais substâncias são designadas princípios ativos.

Jorge (2009, p.16) acrescenta ainda, que a planta medicinal compõe uma unidade terapêutica, isto é, "todos os princípios ativos formam um fitocomplexo que interage entre si e com outras moléculas aparentemente inativas". Ainda segundo a autora, este fitocomplexo simboliza a unidade farmacológica integral de uma planta medicinal.

Segundo Jorge (2009), popularmente, uma planta é diferenciada por meio dos sentidos e memorização de aspectos relevantes, tais como: o formato das plantas, das folhas e das flores. Além disso, a estudiosa esclarece que pode ser identificada também pelo cheiro peculiar, por meio da superfície, que pode ser lisa ou áspera e pelo sabor, podendo ser doce, amargo, ácido e tantos outros.

As plantas, de acordo com Jorge (2009) podem divide-se em grupos semelhantes: plantas que cheiram, de beira de estrada e de rio, domésticas e, assim, por diante. A autora esclarece que uma planta pode apresentar um ou mais denominações populares, podendo alterar de região a região e de cultura a cultura. Na verdade, a nomenclatura da planta “(...)é fundamental no trabalho comunitário, é através dele que se dá o reconhecimento popular das plantas" (JORGE, 2009, p. 13)

Alves e Caes (2015) ressaltam, que a história do uso das plantas medicinais relaciona-se com à história da humanidade, uma vez que, o ser humano, quase sempre, buscou na natureza a saída para os seus males.

Em relatos históricos, segundo Kovalski1; Obara; Figueiredo (2011), uma grande parte das civilizações antigas utilizaram plantas para os mais variados tratamentos. De acordo com esses relatos "os hebreus, egípcios e assírios cultivavam ervas medicinais desde o ano 2.300 a.C." (TOMAZZONI et al., 2006 apud Kovalski1; Obara; Figueiredo, 2011, p.02.).

Conforme, Kovalski1; Obara; Figueiredo (2011), durante muito tempo, o conhecimento tradicional acerca das plantas medicinais foi transmitido de geração em geração, de forma oral. Porém os autores esclarecem que, atualmente, mesmo com o avanço da medicina e da tecnologia, muitas pessoas defendem que a utilização das plantas é a forma mais adequada de tratar uma doença. 
Alves e Caes (2015, p.06) ressaltam, que hoje, os profissionais de saúde "demonstram cada vez mais respeito, aceitação e interesse em compreender um universo para o qual os estudos não os prepararam". Na realidade, ainda segundo os pesquisadores, os profissionais reconhecem o uso de recursos populares de seus pacientes e voltam-se a destacar, não mais eficácia ou não de sua utilização, mas a “(...) necessidade de conscientização quanto ao uso de recursos prejudiciais à saúde" (ALVES; CAES, 2015, p. 06).

Sendo assim, Alves e Caes (2015, p.07) concluiem que os conhecimentos populares sobre as plantas “(...) são necessários ao aprofundamento nas pesquisas para que se possa atuar na preservação e divulgação desses saberes de forma que possam beneficiar a sociedade".

\section{Conhecimento popular e cultural sobre lendas e mitos da amazônia}

'O imaginário nas formas narrativas orais populares da Amazônia paraense' são a verdadeira expressão da multiplicidade do viver amazônico, envolvendo as emoções, os sonhos, os devaneios, as aspirações, ideais, realizações e frustrações, encantos e desencantos

(Simões, 2010, p. 01)

Bastos e Aleixo (2014) ressaltam que, na infância escutávamos muitas histórias, contadas pelos mais velhos. Em nossa mente "(...)imagens iam aparecendo, pensamentos sendo formados, comportamentos, aos poucos, normatizados" (Bastos; Aleixo, 2014, p. 238-247). Ainda conforme os autores, essas histórias que eram transmitidas oralmente e foram denominadas de lendas e mitos.

Segundo Simões (2010), em 1994, iniciou a proposta de recolha das lendas e mitos da Amazônia. Esse trabalho recebeu apoio de "(...) pesquisadores, professores, bolsistas e profissionais de diversas áreas do conhecimento, levou ao patamar em que hoje se encontra, ou seja, uma proposta institucionalizada, com o formato de Campus Flutuante”. (SIMÕES, 2010, p.01),

Simões (2010, p.01) elucida, que o Imaginário nas Formas Narrativas Orais Populares da Amazônia Paraense (IFNOPAP) ${ }^{7}$, destinou-se, inicialmente a “ (...) reunir

\footnotetext{
${ }^{7}$ O IFNOPAP é “(...) um projeto da Universidade Federal do Pará que atua de forma integrada com diversas áreas do conhecimento como a Literatura, a Arqueologia, a Linguística, a Sociologia, a Antropologia, etc. O projeto possui vinte e cinco subprojetos e foi idealizado por Maria do Perpetuo do Socorro Galvão Simões, professora adjunta da Universidade Federal do Pará (UFPA) e pelo professor
} 
as várias formas de narrativas orais contadas pelo amazônida (...) numa tentativa de "mapear o que se conta no Pará", para preservação da memória da região". Dessa forma:

(...) o Projeto iniciou em 1994, com o formato de Programa de Pesquisa, tendo sido implantado em seis dos oito Campi Universitários do Interior. Os municípios atingidos foram: Santarém, Castanhal, Abaetetuba, Bragança, Marabá, Cametá, e o Campus- sede da UFPA em Belém. O sistema de Campi Avançados constituiu a estrutura adequada para pesquisa de tão grande alcance, permitindo uma ampla cobertura do território paraense, envolvendo grande número de professores e de estudantes de todas as microrregiões do Pará. O material recolhido possui uma riqueza e diversidade ímpares. Tal fato propiciou inúmeras propostas, organizadas em subprojetos de várias áreas de pesquisa, principalmente, dos Centros de Letras, Ciências Humanas e Educação.

(SIMÕES, 2010, p.01-02, grifo nosso)

O IFNOPAP, de acordo com Sousa (2014), tem atualmente um gigantesco acervo de narrativas orais, que foram recolhidas no nordeste da Amazônia paraense. O projeto possui vários livros publicados, dentre eles, Santarém conta..., Belém conta... , Abaetetuba conta... e Bragança conta...

Além disso, ainda segundo Sousa (2014), o IFNOPAP promoveu o estudo e a publicação do primeiro Dicionário da língua indígena Asurini, que foi, primeiramente, escrito na língua original e posteriormente traduzida para a Língua Portuguesa.

Sousa (2014) ressalta que o IFNOPAP foi e continua sendo tema de muitas pesquisas em vários níveis, desde monografias e dissertação até teses de doutorado. Além disso, o projeto conta também com um acervo repleto de artigos em circulação, bem como, vem realizando oficinas e mini-cursos. O projeto produziu e vem produzindo diversos materiais audiovisuais, tais como: vídeos e curta-metragens conhecidas de modo nacional.

Hoje, o IFNOPAP é referência para os pesquisadores que possuem interesse em estudar as narrativas orais da Amazônia. O projeto passou do caráter regional para o internacional, e interdisciplinar. A coordenadora, já está aposentada pela a UFPA,

Christopher Golder (UFPA), além de ter recebido contribuições de inúmeros outros profissionais e professores de diversas áreas, bem como de mais de setenta e três bolsistas e dois mil contadores de histórias" (Simões, 2012, p. 21 Apud Sousa, 2014, p. 30). 
porém ainda continua bem atuante, por conta do interesse de diversos pesquisadores em estudar essas narrativas orais da Amazônia.

\section{Considerações finais}

Acreditamos ter alcançado nosso objetivo geral que era refletir sobre os diálogos entre o conhecimento popular e científico. Neste trabalho, apresentamos o conhecimento popular das parteiras, esclarecendo a partir de estudos de pesquisadores, que muitas técnicas, utilizadas por elas foram incorporadas pelos médicos, atualmente. Dessa forma, percebemos que o conhecimento popular das parteiras foi e continua sendo relevante, pois o primeiro hospital do

Brasil "Santa Casa de Santos” só foi instalado em 1543, em São Paulo, e como vimos, a parteira já atuava muito antes desse tempo. Na verdade, essa seria "a profissão mais antiga do mundo" (PEREIRA, 2011, p.04).

Além disso, refletimos sobre a importância do conhecimento popular que é proveniente das plantas medicinais, que assim como as parteiras, sua prática é bem antiga, transmitida oralmente de geração em geração. Por muito tempo tal conhecimento foi estigmatizado sendo considerado como "falsos", "mitos". Atualmente, esse pensamento vem mudando, pois, muitos pesquisadores, que se interessam e estudam sobre as plantas medicinais tem considerado extremante relevantes o conhecimento popular proveniente das plantas medicinais, pois de acordo com pesquisas funcionam, tanto como um efeito terapêutico, quanto na produção de medicamentos fitoterápicos. Hoje, são inúmeros as instituições, hospitais e laboratórios que trabalham com as plantas medicinais.

Considerando as lendas e mitos, por muito tempo, elas se apresentaram como "história para boi dormir" ou, até mesmo, "história de carochinha", porém isso também vem mundando. Atualmente essas narrativas, intituladas como narrativas orais da Amazônia tem sido, como vimos, temas de monografias, dissertações de mestrados e, até mesmo, teses de doutorado.

Dessa forma, mostramos que, atualmente, há uma (re) significação do conhecimento popular, pois, como já mencionamos, na ciência moderna, havia uma preocupação em classificar o conhecimento em "científico" e "não-científico". Os verbos que imperavam nessa ciência eram: classificar, conceituar, verificar. Por outro 
lado, com o surgimento da ciência pós-moderna, isso vem mudando, pois, a preocupação dos pesquisadores não está em tão somente classificar o conhecimento, mas em refletir, indagar e perceber que, tanto o conhecimento popular, quanto o científico contribuem para o processo de construção da inteligência humana.

Sendo assim, neste trabalho, buscamos demostrar também a importância de não apenas incluir os conhecimentos populares na esfera acadêmica, mas de valorizá-los, para que, continuem estabelecendo um diálogo entre eles, como vem ocorrendo nos últimos anos.

$\mathrm{Na}$ verdade, estabelecer esses diálogos entre o conhecimento popular e o científico, nada mais é, do que realizar a justiça, pois durante muito tempo "o saber popular" foi desprezado da sociedade, isto é, excluiu-se o conhecimento dos pobres, dos ribeirinhos, dos marginalizados. $\mathrm{Na}$ verdade, isso tudo ocorreu por conta da ciência hegemônica, que se pautava na razão indolente, ou seja, a ciência moderna.

Finalizando o nosso trabalho, gostaríamos de esclarecer que essa pesquisa não visa criticar o conhecimento científico, nem tão pouco o excluir, como o que ocorreu com o conhecimento popular, pois afinal, somos participantes e contribuintes do conhecimento acadêmico-científico, mas sim mostrar que o conhecimento popular pode dialogar, e muito bem, com o conhecimento científico, isto é, existe espaço para os dois conhecimentos. Não é necessário excluir um e valorizar o outro, mas perceber que todos têm sua importância e peculiaridade. Contribuindo assim, para uma humanidade mais justa, que leve em conta os princípios éticos e morais, que respeite as diversidades culturais e sociais e que levem em conta os direitos humanos.

\section{Referências}

ALVES, Hayala Katarine Dias Ribeiro; CAES, André Luiz. Conhecimentos e práticas do uso de plantas medicinais com abordagem etnobotânica, no município de morrinhosgoiás: estudo de caso. In: XXVIII Simpósio Nacional de História na cidade de Florianópolis/SC. Anais XXVIII Simpósio Nacional de História na cidade de Florianópolis/SC, 2015.

JORGE, Schirlei da Silva Alves. Plantas medicinais Coletânea de saberes, 2009.

KOVALSKI, Mara Luciane; OBARA, Ana Tiyomi; FIGUEIREDO, Marcia Camilo. Diálogo dos Saberes: O conhecimento Científico e Popular das Plantas Medicinais na Escola. In: VIII Encontro Nacional de Pesquisa em Educação em Ciências e ICIEC 
Congresso Iberoamericano de Investigación en Enseñanza de las Ciencias, 2011, Campinas. Anais VIII Enpec, 2011.

BASTOS, Cínthia de Oliveira; ALEIXO, Marcos Frederico Krüger. Memória e Arquivo Em Narrativas Amazônicas. In: XIV Encontro da ABRALIC, Universidade Federal do Pará (UFPA- Belém), Anais XIV Encontro da ABRALIC, 2014.

PEREIRA, Marina Santos. O Trabalho da Parteira: um saber iniciado e compartilhado entre as mulheres. In: V Jornada Internacional de Políticas Públicas - V JOINPP, 2011, São Luís/MA. Anais da V Jornada Internacional de Políticas Públicas: Estado, Desenvolvimento e Crise do capital, 2011.

SANTOS, Boaventura de Souza; FILHO, Naomar de Almeida. A Universidade no Século XXI: Para uma Universidade Nova. Coimbra: Almedina, 2008. http://www.boaventuradesousasantos.pt/media/A\%20Universidade\%20no\%20Seculo\% 20XXI.pdf. Acesso em: 12 de jul. de 2017.

A defesa da descolonização das universidades foi o mote da conferência do português Boaventura de Sousa Santos na UFMG. Material Audiovisual.

Disponível em: https://educezimbra.wordpress.com/2017/07/02/descolonizar-asuniversidades-para-uma-ecologia-dos-saberes/. Acesso em 26 dezembro 2017.

. Um discurso sobre as ciências / Boaventura de Sousa Santos. - 5. ed. - São Paulo: Cortez, 2008. Disponível em: https://edisciplinas.usp.br/pluginfile.php/1979672/mod_resource/content/1/SANTOS\%2 0Um\%20discurso\%20sobre\%20as\%20ci\%C3\%AAncias_LIVRO.pdf. Acesso em: 12 de jul. de 2017.

SILVA, Severino Felipe da; NETO, José Francisco de Melo. Saber popular e saber científico. Revista Temas em Educação, v. 24, p. 137-154, 2015. Disponível em: http://periodicos.ufpb.br/index.php/rteo/article/viewFile/25060/14567. Acesso em: 12 de jul. de 2017.

SOUSA, Greubia da Silva. Dos grimm ao ifnopap: entre o ouvido e o traduzido. 2014. 102 f. Dissertação (Programa de Pós-Graduação em Linguagens e Saberes na Amazônia -PPGLS), UFPA-Bragança, 2014. Disponível em: http://pplsa.propesp.ufpa.br/ARQUIVOS/dissertacoes/2012/DOS\%20GRIMM\%20AO \%20IFNOPAP $\% 20$ ENTRE $\% 200 \% 20$ OUVIDO $\% 20 \mathrm{E} \% 200 \% 20$ TRADUZIDO $\% 20(\mathrm{Gr}$ eubia\%20da\%20Silva\%20Sousa).pdf. Acesso em: 12 de jul. de 2017.

SIMÕES, Maria do Socorro. Mitos e lendas da Amazônia paraense. Revista Litteris, v. 5, p. 1-11, 2010. 